\title{
A Simple Model of Commodity Taxation and Cross-border Shopping
}

\author{
Nielsen, Søren Bo
}

Document Version

Final published version

Publication date:

1998

License

CC BY-NC-ND

Citation for published version (APA):

Nielsen, S. B. (1998). A Simple Model of Commodity Taxation and Cross-border Shopping. Department of Economics. Copenhagen Business School. Working Paper / Department of Economics. Copenhagen Business School No. 13-98

Link to publication in CBS Research Portal

\footnotetext{
General rights

Copyright and moral rights for the publications made accessible in the public portal are retained by the authors and/or other copyright owners and it is a condition of accessing publications that users recognise and abide by the legal requirements associated with these rights.

\section{Take down policy}

If you believe that this document breaches copyright please contact us (research.lib@cbs.dk) providing details, and we will remove access to the work immediately and investigate your claim.
} 


\section{Institut for Nationaløkonomi}

Handelshøjskolen i København

Working paper 13-98

A SIMPLE MODEL OF COMMODITY TAXATION AND CROSS-BORDER SHOPPING

Søren Bo Nielsen

Department of Economics - Copenhagen Business School Nansensgade 19, 5. DK - 1366 København K. 


\title{
A simple model of commodity taxation and cross-border shopping
}

\author{
Søren Bo Nielsen \\ Economic Policy Research Unit \\ and Copenhagen Business School
}

This version

November 1998

\begin{abstract}
This paper sets up a simple model of commodity taxation and cross-border shopping. Two countries, differing in geographical extent, engage in tax competition originating in the opportunities for cross-border shopping. Both tax competition and various coordination initiatives are examined. Then follow two extensions: (i) inclusion of costs of transportation for goods; (ii) inclusion of border inspection. These extensions allow us to conclude that both a drop in transportation costs and abolishment of border control intensify commodity tax competition and lower tax rates and revenues. The qualitative results for coordination measures also hold for the extended versions of our model.
\end{abstract}

${ }^{*}$ A longer version of this paper is available as an EPRU Working Paper. Comments from Vidar Christiansen, Andreas Haufler, Mick Keen, Ann-Sofie Kolm, Ronnie Schöb, as well as from participants in a seminar at Universität Rostock, the Warwick Summer Research Workshop, and the 54th IIPF Conference in Cordoba are gratefully acknowledged. The activities of EPRU are financed by a grant from The Danish National Research Foundation. Address of author: Department of Economics, Nansensgade 19, 5., DK-1366 Copenhagen K, Denmark. 


\section{Introduction}

This paper examines commodity tax competition and coordination in a setting with cross-border shopping. The aim of the paper is to characterize, in the simplest possible way, commodity tax games, and derive to what extent various forms of coordination can be beneficial to the countries involved. A further objective is to extend the simple benchmark model to include costs of transportation of not only persons, but also goods, and to incorporate border inspection to contain illegal cross-border shopping.

The paper contributes to a growing literature on commodity tax systems. It is most closely related to previous work on commodity taxes and cross-border trade, in particular Kanbur and Keen (1993) and Haufler (1996). ${ }^{1}$ These articles characterize noncooperative commodity taxation, emphasizing asymmetries between countries in tax competition; Kanbur and Keen focus on differences in population densities ${ }^{2}$, while Haufler investigates the implications of different preferences for public goods. Instead of these asymmetries, we underline differences in the geographical extent of countries, and it turns out that our benchmark model becomes significantly simpler than its predecessors. Besides investigating issues also covered by Kanbur and Keen (1993) and Haufler (1996), the simplicity of our basic model allows us to devote our attention to pertinent new topics.

The motivation for our work lies in the many examples of cross-border shopping around the world and in particular in the initiatives already undertaken or being contemplated by the EU Commision in the area of coordination of commodity taxes. The appropriate taxation of commodities in Europe has been debated at varying intensity over the last four decades or so (for an account, see Fehr et al. (1995) and Keen and Smith (1996)). To begin with, the preferred principle for commodity taxation - origin-based or destination-based taxation - was in focus. Following the moves toward an Internal Market in the EC, sealed by the accept of the proposals in the White Paper (cfr. EC Commission (1985)), the discussion shifted towards some form of harmonization of the destination-based commodity taxes in the EC. Initially, the ideas centered around defining a band, in which the standard Value-Added Tax (VAT) rates ought to lie, and similar bands (or even uniformity of rates) for excise taxes on tobacco, liquor, etc. Later on, the outcome of this process became a floor on the standard VAT rate, together with a

\footnotetext{
${ }^{1}$ Earlier work on commodity tax competition can be found in Mintz and Tulkens (1986), deCrombrugghe and Tulkens (1990) and Lockwood (1993).

${ }^{2}$ Trandel (1994) likewise investigates commodity taxation in two countries with differing population densities.
} 
maximum (2) on the number of additional, reduced VAT rates (for a description of the process, see Keen (1993)).

In this paper we shall, among other things, examine the effects of such tax coordination proposals within a simple framework of commodity taxation and cross-border shopping. Our basic model contains two countries of different size, with an open border between them. Citizens in the two countries purchase one unit each of a composite commodity, either at home or across the border. The tax authorities in the two countries levy commodity taxes so as to maximize tax revenue. In the noncooperative commodity tax equilibrium, the large country sets the higher tax rate, but the small country features the higher tax revenue per capita. Further, the level of commodity taxes increases with the level of transportation costs for people engaging in cross-border shopping. The acts of coordination of commodity taxes which we investigate are the following: marginal reform, rate harmonization, and a minimum tax rate. Small increases in commodity taxes enhance tax revenues in both countries, whereas harmonization of tax rates always will lower tax revenue in the small country (and that may happen in the large country as well). Finally, a minimum tax will have the property of increasing tax revenue in both countries.

Previous models of commodity tax competition and cross-border shopping have been accused of emphasizing transportation costs on the part of individuals, leaving aside the question of costs of transportation of goods and the implications of cross-border shopping for goods markets. Therefore, we extend the benchmark model in the second part of the paper to take into account costs of transportation of goods and the associated effects of cross-border shopping on market prices of goods. Costs of transportation of goods will generally lead to higher commodity tax rates than if there were no such costs. In the small country they will also lead to relatively high goods prices close to the border and to the generation of (location-specific) profits to sellers. Surprisingly, an increase in the ability on the part of the small country to tax away such profits will likely imply a reduction of total tax revenue in that country because of a strong strategic reaction in the tax rate of the large country.

In the last part of the paper we briefly look at those forms of cross-border shopping which are illegal and which therefore will induce authorities to inspect border traffic in order to catch commodity tax evaders. This leads us to a discussion of how tax setting and the noncooperative commodity tax equilibrium are affected by a positive probability of detection. We show that the introduction of border control causes the noncooperative 
taxes as well as net tax revenues ${ }^{3}$ to increase in the two countries. The effect of border inspection on the amount of cross-border shopping is ambiguous, though, as its sign depends on the marginal cost of inspection.

While the two extensions complicate our benchmark model considerably, we are nevertheless able to confirm the benchmark model's insights as to the effects of coordination of commodity taxation.

The paper is organized in the following way: Section 2 sets up the basic model, after which it outlines the consequences of tax competition and examines possible coordination measures. Then, sections 3 and 4 introduce transportation costs for goods and border inspection, respectively. The final section 5 concludes.

\section{The basic model}

The model has two countries, together represented by the interval $[-1,1]$. Population density is unity in both countries. The larger of the two extends from -1 to some border parameter $b>0$, while the smaller one extends from $b$ to $1 .{ }^{4}$ Hence, population sizes are $1+b$ and $1-b$, respectively. The relative size of the small country is measured by the ratio $(1-b) /(1+b)$; it decreases when the border parameter $b$ rises, and vice versa.

There is one (composite) good in the world. Each individual purchases one unit of the good, when his reservation price exceeds the price of the good. Reservation prices in the large and the small country are denoted by $V$ and $v$, respectively. We shall generally assume that these reservation prices are high enough that for the relevant taxinclusive commodity prices resulting in the two countries, all individuals will indeed wish to purchase the commodity.

With a constant number of individuals and with the guarantee that all individuals will purchase one unit of the good, we may as well ignore the production cost of the good and set it equal to zero. Commodity taxes are specific taxes, and they are levied at the rates $T$ in the large and $t$ in the small country. Goods prices are then simply the relevant tax rates. For an individual to travel to the border to purchase the good abroad, a transportation cost of $d$ per unit distance travelled ${ }^{5}$ is incurred. While some individuals may choose this option, the rest purchase the good in the place of residence.

\footnotetext{
${ }^{3}$ Taking fines and inspection costs into account, where relevant.

${ }^{4}$ We take $b$ to be positive in what follows, although all formulas will be valid for $b=0$, too. Further, there are usually no problems with perceiving $b$ to be negative, so that the two countries switch roles in terms of size.

${ }^{5}$ The cost includes the return part of the trip as well.
} 
An individual in the large country will purchase the good at the border, if the surplus obtained by doing so, $V-t-d S$, where $S$ stands for the necessary distance travelled, exceeds the surplus from buying at home, $V-T$. Hence, those with a distance

$$
S \leq S^{*}=\frac{T-t}{d}
$$

will opt for cross-border shopping (for $T>t$; if $T \leq t$, no-one will do so).

Similarly, citizens in the small country for whom the distance to the border $s$ fulfils

$$
s \leq s^{*}=\frac{t-T}{d}
$$

will choose to shop abroad (again, if $t \leq T$, no-one will).

For simplicity, the objective on the part of tax authorities in the two countries is taken to be maximization of tax revenue. ${ }^{6}$ Given that every individual would accept a price anywhere up to the reservation price, it will be revenue-maximizing for authorities to set the commodity tax rate equal to the relevant reservation price, if the border between the two countries is closed, that is

$$
T^{c}=V, \quad t^{c}=v
$$

But with an open border, the two countries will have an incentive to undercut each other in order to capture tax revenue from foreigners who are led to shop across the border. This mechanism prevents tax authorities from squeezing out the full reservation prices from consumers.

Incorporating cross-border shopping, the number of residents of the large country shopping abroad is $(T-t) / d$, if $T>t$. If on the contrary $T<t,(t-T) / d$ small country individuals shop in the large country. Hence, tax revenues in the large and small country amount to, respectively,

$$
R(T, t)=T\left[1+b+\frac{t-T}{d}\right], \quad r(t, T)=t\left[1-b+\frac{T-t}{d}\right]
$$

They depend on the exogenous values of the border parameter $b$ and the transportation cost parameter $d$.

\footnotetext{
${ }^{6}$ This is also the case in Kanbur and Keen (1993), whereas Haufler (1996) assumes that authorities maximize preferences over private and public goods. Trandel (1994) extends the Kanbur-Keen model by allowing authorities to maximize welfare of domestic citizens in lieu of tax revenue. He demonstrates that this modification will not affect the qualitative conclusion as to which country levies the higher commodity tax. Haufler (1996) shows that the effects of coordination become somewhat less clear, when authorities maximize the utility of residents rather than tax revenue.
} 
The non-cooperative tax equilibrium

Setting derivatives of tax revenues with respect to own taxes equal to zero, we derive

$$
T=\frac{d}{2}(1+b)+\frac{t}{2}, \quad t=\frac{d}{2}(1-b)+\frac{T}{2}
$$

These are best responses of one country to tax policy in the other country (reaction functions).

The reaction functions are illustrated in Figure 1. The two tax rates are on the axes. It clearly emerges that at the Nash equilibrium where the reaction functions cross, the large country commodity tax is the higher one. This is stated in Proposition 1 which also contains the solutions for the Nash commodity tax rates, the extent of cross-border shopping, and tax revenues:

PROPOSITION 1. (a) The Nash commodity tax equilibrium is well-defined and unique. It has a higher rate of tax in the large country than in the small country, the rates being

$$
T^{N}=d\left(1+\frac{b}{3}\right), \quad t^{N}=d\left(1-\frac{b}{3}\right)
$$

The Nash commodity tax rates are proportional to the transportation cost parameter $d$. Further, an increase in the border parameter $b$, rendering the large country even larger, widens the difference between the two tax rates.

(b) The amount of cross-border shopping is $\left(T^{N}-t^{N}\right) / d=2 b / 3$.

(c) Nash tax revenues are

$$
R\left(T^{N}, t^{N}\right)=d\left(1+\frac{b}{3}\right)^{2}, \quad r\left(t^{N}, T^{N}\right)=d\left(1-\frac{b}{3}\right)^{2}
$$

The large country collects the larger tax revenue. With respect to per capita tax revenue, it is the other way around. Both absolute and per capita tax revenues are proportional to the transportation cost parameter $d$. The absolute tax revenue of the large country increases with the border parameter $b$, while the absolute revenue of the small country falls. Conversely, the per capita revenue of the large country falls and that of the small country rises, if $b$ is increased.

Interestingly, the extent of cross-border trade is independent of the transportation cost parameter $d$. On one hand, a higher transportation cost parameter directly lowers crossborder shopping. On the other hand, it leads to higher commodity taxes and especially 
a greater difference between the two tax rates, and this raises cross-border shopping to such an extent as to just offset the former effect.

A drop in the border parameter $b$ clearly represents a reduction in the disparity between the size of the two countries. We therefore conclude that reducing the disparity between the two countries will not be Pareto improving, neither with respect to absolute nor with respect to per capita revenue. ${ }^{7}$

\section{Tax coordination}

To approach issues of international commodity tax coordination let us examine three experiments. The first is a marginal tax reform of the form $(d T, d t)$, away from the Nash equilibrium, in which $d T$ and $d t$ are both positive. The second is commodity tax coordination in the form of complete harmonization of tax rates (the strong form of the 'approximation' urged by the EC Commission in the late 1980s). We imagine that both countries adopt a tax rate $\tau$ which is a weighted average of the two Nash tax rates, $\tau=a T^{N}+(1-a) t^{N}$, with $a$ being between 0 and 1 . With the same tax rate in both countries, cross-border shopping will come to an end. Finally, the third act of coordination which has been widely debated and actually implemented in the EU is that of a mandated minimum tax. We now imagine that both countries are required to levy the commodity tax at least at a rate $\tau$, where $\tau$ lies between the two Nash tax rates $t^{N}$ and $T^{N}$. For these three coordination experiments we can show the following:

PROPOSITION 2. (a) A small multilateral reform, $(d T>0, d t>0)$, is Pareto improving in the sense that tax revenues in both countries rise.

(b) Harmonization of commodity tax rates can never benefit the small country. If the harmonized tax rate is large enough, $\tau>\tau^{*}=d(1+b / 3)^{2} /(1+b)$, harmonization will be beneficial for the large country.

(c) A minimum tax requirement $t, T \geq \tau$, where $\tau \in\left(t^{N}, T^{N}\right)$, will benefit both countries.

Proof: (a) Changes in own tax rates (e.g. in $T$ in the large country) have no effects, as they were optimized that way, but the cross-effects of increases in tax rates are clearly positive.

\footnotetext{
${ }^{7}$ This result is at variance with Proposition 7 of Kanbur and Keen (1993), due to a different source of asymmetry between countries in this paper. Proposition 1 above, however, qualitatively corresponds well to Propositions 1-6 in their article.
} 
(b) Under harmonization the tax revenue of the small country attains its maximum value for $\tau=T^{N}$, in which case $r(\tau, \tau)=r\left(T^{N}, T^{N}\right)=d(1+b / 3)(1-b)$. But this value is smaller than the value $r\left(t^{N}, T^{N}\right)=d(1-b / 3)^{2}$ attained in the non-cooperative equilibrium. Regarding the large country, the revenue comparison is between $R(\tau, \tau)=$ $(1+b) \tau$ and $R\left(T^{N}, t^{N}\right)=d(1+b / 3)^{2}$. The two are equal for the borderline value of $\tau^{*}=d(1+b / 3)^{2} /(1+b)$ which is easily seen to lie in the interval between $t^{N}$ and $T^{N}$. Hence, if only the agreed-upon common commodity tax rate is high enough, the large country will gain from the harmonization initiative.

(c) The best response for the large country is $T(\tau)=\frac{1}{2}[d(1+b)+\tau]$, whence the tax base for the small country tax becomes $1-b+(T(\tau)-\tau) / d=(3 / 2)-(b / 2)-(\tau / 2 d)$. The tax revenue in the small country is clearly concave in $\tau$. For $\tau=t^{N}$, the minimum tax is just not binding, and the small country derives unchanged revenue. The derivative of the tax revenue with respect to $\tau$ in this point is positive. Furthermore, for $\tau=T^{N}$ the small country collects a higher revenue than in the initial non-cooperative equilibrium, and the same must therefore be true for all intermediate values of $\tau$. As to the large country, since its tax revenue can be written as $d[(1+b) / 2+\tau /(2 d)]^{2}$, it will clearly collect a higher revenue than in the non-cooperative equilibrium for all $\tau>t^{N}$.

In Figure 1, the marginal tax reform implies a north-easterly move. Clearly, this will benefit both countries. Harmonization of taxes is tantamount to choosing a point on the $45^{\circ}$ line segment between points $A=\left(t^{N}, t^{N}\right)$ and $B=\left(T^{N}, T^{N}\right)$. It is easily seen that there is no way that this initiative can benefit the small country.

The intuition for this result is that wiping out the benefits from large country consumers shopping and paying taxes in the small country will be more important for it than the ability to levy a higher commodity tax on its own residents. For the large country, the gains are in terms of being able to impose taxes on those domestic residents which previously went shopping in the small country. If only harmonization does not greatly reduce its tax rate, the losses due to a lower tax will be dominated by the gains just alluded to.

The minimum tax is likewise illustrated in Figure 1 by a move from the Nash equilibrium $N$ up the large country's reaction curve. This is so because it is the small country which will be constrained by the minimum tax rate, while the large country will be free to respond. With a minimum rate of $\tau$, the response of the large country, $T(\tau)$, will be greater than $\tau$, but given that the slope of the reaction curve is equal to one half, the 
difference between $T(\tau)$ and $\tau$ itself will be smaller than the corresponding difference between tax rates in the Nash equilibrium. Figure 1 indeed suggests that the minimum tax requirement can be to the advantage of both countries.

This completes our description of the properties of the benchmark model. In the next two sections we extend the basic model to incorporate transportation costs for commodities, and border inspection, respectively.

\section{Incorporating costs of transporting goods}

The benchmark model above included costs of transportation of individuals in order to nail down the extent of cross-border shopping. In contrast, it was implicitly assumed that there were no costs of transporting goods to the border or to other places where demand might exceed production.

It has often been objected that taking into account the costs on the part of individuals when they move to the border to purchase goods, but not costs of moving goods, is somewhat awkward. Fortunately, our benchmark model is simple enough as to allow us to remedy this deficiency. Doing so is the agenda for this section.

When cross-border shopping exists in our model we interpret this to imply that persons literally move to the border in order to acquire goods which they then bring back home. The flip side of this is that there are mechanisms ensuring that goods are made available at the border for cross-border shoppers. To the extent that this requires moving goods around, we now assume that costs of transportation are involved.

In our benchmark model, where we ignored such transportation costs, there was no reason for specifying where goods are produced. Now we must be explicit about this in order to figure out what goods movements are necessary to accomodate crossborder shopping. We shall assume that the production of goods is uniformly distributed over the two countries, so that in the absence of cross-border shopping production and consumption will coincide in every location. ${ }^{8}$

Let $e$ denote the cost of transporting one unit of the good over one unit of distance. Quite realistically, we shall assume in the following that $e<d$. If some unit of the good is produced in a location $w<b$, say, and subsequently shipped to the border to be purchased by an individual living at point $z<b$, then the travel of that individual gives rise to costs $d(b-z)$, whereas transportation of the good to the market costs $e(b-w)$.

\footnotetext{
${ }^{8}$ Without increasing returns to scale or other forces of agglomeration present, and with a uniformly distributed population, this is as good an assumption as any.
} 
What difference will accounting for transportation costs of goods make for the noncooperative commodity tax equilibrium, for tax revenues, and for the amount of crossborder shopping?

To answer this question we first have to derive the equilibrium commodity acquisition pattern and the associated market prices. Assuming perfect competition among sellers, these market prices are everywhere equal to marginal cost (of transportation and commodity tax). ${ }^{9}$ To describe the nature of the outcome we apply a heuristic argument below. We proceed in steps, making a series of observations. ${ }^{10}$

[1]. Far from the border in the large country, the tax-inclusive price of the good will be equal to the large country commodity tax rate $T$.

[2]. Similarly, far from the border in the small country, the market price will be unaffected by cross-border shopping and equal to $t$, the small country commodity tax rate.

[3]. Some citizens in the large country will be exactly indifferent between buying locally at the price $T$ and purchasing the good at the border at the price there, called $p_{b}$. Denoting their residence by $x(x<b)$, the transportation cost incurred by these people is $(b-x) d$. Hence, $x$ must fulfil

$$
(b-x) d+p_{b}=T
$$

[4]. The market price at the border will exceed the small country tax $t$. This is because goods sold there to foreigners effectively have to be transported from that part of the large country, where residents shop at the border, and where there no longer is any local demand for goods (i.e., the area between $x$ and $b$ ). As it is costly to move goods to the border, the market price there will reflect this. In fact, the market price $p_{b}$ will fully reflect the cost of transporting the marginal unit of the good, i.e. the unit with the longest distance of transportation. This is a unit produced at $x$, whence the associated transportation cost is $e(b-x)$. In other words,

$$
p_{b}=t+(b-x) e
$$

\footnotetext{
${ }^{9}$ For a discussion of border trade under imperfect competition see Christiansen (1994) and Trandel (1994).

${ }^{10}$ What follows is predicated on the assumption that in equilibrium it is the large country which will levy the commodity tax at the higher rate. It can be seen that entertaining the opposite assumption will lead to a contradiction.
} 
[5]. In the small country, those that live at the border and shop there pay the border price of $p_{b}$. Prices further into the small country are determined by the requirement that in the equilibrium, there should be no incentive for sellers at (or in the neighborhood of) the border to acquire goods from producers further into the small country and then sell them in the border region. What this implies is that $p_{b+s}=p_{b}-e s$ for a distance $s$ from the border. (At the same time, it should be at least as large as the commodity tax $t$. $)^{11}$

[6]. While close to the border the market price lies above the commodity tax in the small country, at a certain point the two will coincide. Calling this point $y$, we then have

$$
p_{b}-e(y-b)=t
$$

The situation just described in the six steps is depicted in Figure $2 .{ }^{12}$ In the outer regions in the two countries market prices are at $T$ and $t$, respectively. The border price is somewhere in between, and into the small country the price declines at the rate $e$. On the other side of the border, in the region between $x$ and $b$, the local price $(T)$ is irrelevant - people shop at the border at the price $p_{b}$, and the goods produced in this region are transported to the border. ${ }^{13}$ The dotted line indicates total costs of acquiring the good for people living in this area, the slope of the line being $-d$.

In expressions (7)-(9) above we have enough information to find $x, y$ and $p_{b}$. We obtain

$$
b-x=y-b=\frac{T-t}{d+e}
$$

and

$$
p_{b}=\frac{e T+d t}{d+e}
$$

It is obvious that the border price $p_{b}$ is a weighted average of the two commodity taxes with unit transportation cost of goods, respectively individuals, entering the weights (and that it degenerates to $t$ for $e$ going to zero). It is likewise evident that the equilibrium market price schedule will give rise to some pure profits being earned by sellers of the

\footnotetext{
${ }^{11}$ Further, there should be no incentive for those living at the border (or indeed large country crossborder shoppers) to move inside the small country in order to acquire the good. Hence, the market price at the distance $s$ from the border in the small country, $p_{b+s}$, should fulfil $p_{b+s} \geq p_{b}-d s$. However, as $d>e$, this requirement will be redundant.

${ }^{12}$ The reader may convince himself that the situation in Figure 2 indeed is an equilibrium; no economic agent, consumer or seller, has any incentive to act differently.

${ }^{13}$ It is interesting to note here that the bulk of the beers, cigarettes, sugar and many other goods which Danes purchase south of the border with Germany are indeed produced in Denmark.
} 
small country at and in the neighborhood of the border. At the border, the number of customers is $(T-t) /(d+e)$; they purchase the good at price $p_{b}$, but the average taxinclusive cost to sellers of supplying these goods is only $t+e(T-t) /[2(d+e)]$. Hence, these sellers will earn a pure profit of $(e / 2)[(T-t) /(d+e)]^{2}$. Similarly, over the range $(b, y)$, the price of the good varies from $p_{b}$ down to $t$, whereas the tax-inclusive cost of satisfying the local demand is only $t$. Pure profits of the amount $(e / 2)[(T-t) /(d+e)]^{2}$ are then harvested by sellers in this area. ${ }^{14}$ Accordingly, total profits on the part of sellers in the small country are $e[(T-t) /(d+e)]^{2}$.

The question now is whether and to what extent these profits can be sucked up by tax authorities in the small country. We denote the rate of profit tax there by $\pi$, with $0 \leq \pi \leq 1$. The profit tax rate is treated as exogenous to the setting of commodity taxes.

Commodity tax revenue in the large country becomes

$$
R(T, t)=T\left[1+b-\frac{T-t}{d+e}\right]
$$

while the total (commodity plus profit) tax revenue of the small country becomes

$$
\tilde{r}(t, T ; \pi)=t\left[1-b+\frac{T-t}{d+e}\right]+\pi e\left[\frac{T-t}{d+e}\right]^{2}
$$

From these revenue expressions we next derive reaction functions,

$$
T=\frac{(d+e)}{2}(1+b)+\frac{t}{2}, \quad t=\frac{(d+e)^{2}(1-b)}{2(d+(1-\pi) e)}+\frac{T(d+e(1-2 \pi))}{2(d+(1-\pi) e)}
$$

The Nash commodity tax rates are given in ${ }^{15}$

PROPOSITION 3. Taking into account costs of transportation of goods (of $e$ per unit of distance) and profit taxation (at the rate $\pi$ ) yields a Nash commodity tax equilibrium with

$$
\begin{aligned}
T & =(d+e)\left[1+\frac{b}{3}\left(1-\frac{4 \pi e}{3(d+e)-2 \pi e}\right)\right] \\
t & =(d+e)\left[1-\frac{b}{3}\left(1+\frac{8 \pi e}{3(d+e)-2 \pi e}\right)\right]
\end{aligned}
$$

\footnotetext{
${ }^{14}$ Again, it is interesting to note that casual observations of prices of relevant goods in Northern Germany close to the Danish border confirm this result. Prices are highest just at the border and then decline, as you drive into Germany.

${ }^{15}$ In the special case of $\pi=0$, the tax rates are $T=(d+e)(1+b / 3)$ and $t=(d+e)(1-b / 3)$, respectively, and obviously of the same form as those in Proposition 1. However, as soon as the profit tax $\pi$ is positive, the tax rates are qualitatively different from those of the case without costs of transportation for goods.
} 
Scrutiny of the two tax rate formulas yields the next Proposition, PROPOSITION 4. (a) The higher is the ability on the part of tax authorities in the small country to capture profits generated because of costs of transportation for goods, the lower are Nash non-cooperative commodity tax rates.

(b) Unless the border parameter $b$ and the profit tax rate $\pi$ are both close to unity, the greater are costs of transporting goods, the higher are the Nash non-cooperative commodity tax rates.

Proof: (a) Straightforward differentiation of formulas (14a-b). (b) Direct differentiation of formula (14b) wrt. $e$ yields

$$
\frac{d t}{d e}=1-b \frac{3(d+e)^{2}+4 \pi(d+e)(2 d+e)-4 \pi^{2} e^{2}}{[3(d+e)-2 \pi e]^{2}}
$$

This expression is decreasing in both $b$ and $\pi$. But it will clearly be positive, if $b$ is small enough, or if $\pi$ is small enough. To see that it may become negative, if both $b$ and $\pi$ are large enough, let $\pi=1$, in which case the ratio following $b$ becomes equal to $\left[\left(11 d^{2}+18 d e+3 e^{2}\right) /\left(9 d^{2}+6 d e+e^{2}\right)\right]>1$. If then $b$ exceeds the inverse of this number, the effect of the increase in $e$ on $t$ becomes negative. Conversely, let $b$ be very close to unity. Then the derivative becomes proportional to $(d+e)^{2}(6-8 \pi)-8 \pi e[d+e(1-\pi)]$, and this expression obviously becomes negative for $\pi$ sufficiently close to unity. Next, differentiation of (14a) wrt. $e$ gives

$$
\frac{d T}{d e}=1+b \frac{3(d+e)^{2}-4 \pi(d+e)(d+2 e)+4 \pi^{2} e^{2}}{[3(d+e)-2 \pi e]^{2}}
$$

Close inspection of this expression will establish that it will always be positive for $b$ and $\pi$ between zero and one.

It is evident from the proof that the case in which an increase in $e$ leads to a drop in one of the tax rates (that of the small country) should be regarded as exceptional. ${ }^{16}$ In general, therefore, relatively high costs of transportation for commodities provide a shield against cross-border shopping and commodity tax competition. Further, the opportunity of capturing part of the profits which accrue to sellers of the commodity in the small country makes undercutting more attractive for the small country, limiting its commodity tax - and thus that of the large country as well.

\footnotetext{
${ }^{16}$ For instance, an increase in $e$ from zero will only lead to a lower small country tax rate, if with a border parameter of almost unity the profit tax rate exceeds $3 / 4$, or, alternatively, if at a profit tax rate of unity the border parameter lies above $9 / 11$.
} 
In Figure 3 we have drawn first, the two reaction curves corresponding to the case of no goods transportation costs, $e=0$. These two curves, labelled $L_{o}$ and $l_{o}$, are the same as the reaction curves in Figure 1. The associated Nash equilibrium is point $N_{o}$ in the figure. Introducing a transportation cost $e>0$ in the figure, assuming a zero profit tax, $\pi=0$, leads to a movement to the right of the large country's reaction curve, while the (relevant part of the) small country reaction curve moves up. This produces the Nash equilibrium, point $N_{e}^{o}$. Clearly, both commodity taxes are higher at that equilibrium than at point $N_{o}$. In which way will the location of the reaction curves be affected by the incorporation of the profit tax? From the expressions in (13) above, we see that the large country reaction curve will stay put. That of the small country will, however, rotate clock-wise around its point of intersection with the $45^{\circ}$ line. As a result, the Nash equilibrium will move down the large country's reaction curve towards point $N_{e}^{1}$, where the profit tax is at its maximum of unity.

From the non-cooperative commodity tax rates in (14a) and (14b) we derive the amount of cross-border shopping:

PROPOSITION 5. The amount of cross-border shopping is given by

$$
\frac{T-t}{d+e}=\frac{2 b}{3}\left[1+\frac{2 \pi e}{3(d+e)-2 \pi e}\right]
$$

The extent of cross-border shopping in the non-cooperative equilibrium is an increasing function of the profit tax rate $\pi$, the border parameter $b$, and (for a positive profit tax) the commodity transportation cost $e$.

The general formulas for tax revenues of the two countries in the non-cooperative equilibrium are, unfortunately, somewhat involved. It is, however, easy to derive

PROPOSITION 6. For low enough values of the profit tax rate in the small country, tax revenues in the two countries increase, if the transportation cost parameter $e$ is raised.

Proof: For a profit tax equal to zero, tax revenues are proportional to $d+e$ and hence increase as $e$ is raised (use (14a-b)). By continuity, the latter property at least holds for small positive values of $\pi$ as well.

Concerning the dependence of tax revenues in the two countries on the rate of profit tax in the small country, there is a real surprise:

PROPOSITION 7. Starting with a small country profit tax rate of zero, a marginal increase in the rate will reduce tax revenue in the large country. For values of the border 
parameter $b$ lower than $3 / 4$, the increase in the profit tax will also lower total tax revenue in the small country.

Proof: Using (12a) and (14a-b), the large country's tax revenue in the non-cooperative equilibrium can be written as $R(T, t)=T^{2} /(d+e)$. As a higher small country profit tax leads to a lower commodity tax rate in the large country (cfr. (14a)), it will also imply a lower tax revenue there. In the small country, the total tax revenue in the non-cooperative equilibrium changes as follows,

$$
\frac{d \bar{r}}{d \pi}=\frac{\partial \bar{r}}{\partial \pi}+\frac{\partial \bar{r}}{\partial t} \frac{\partial t}{\partial \pi}+\frac{\partial \bar{r}}{\partial T} \frac{\partial T}{\partial \pi}
$$

In addition to the direct effect of an increase in $\pi$ on $\bar{r}$ there are indirect effects via changes in the two tax rates. In the Nash equilibrium, of course $\partial \bar{r} / \partial t=0$, whence the second term in (16) drops out. The first term is positive, $\partial \bar{r} / \partial \pi=4 e b^{2} / 9>0$, as is $\partial \bar{r} / \partial T$, $\partial \bar{r} / \partial T=1-b / 3$. The effect of an increase in $\pi$ on $T$ is negative, $\partial T / \partial \pi=-4 e b / 9$. Inserting these expressions into (16) it becomes clear that it will indeed be negative, as long as the border parameter $b$ is less than $3 / 4$.

To get some intuition for the Proposition, note that the higher is the profit tax rate, the greater is the incentive for the small country to attract large country customers via a low commodity tax rate. To partially counter this, the large country lowers its tax, too, implying in the end a lower tax revenue there. In the small country, the commodity tax trades off benefits from a higher rate against the loss of tax base and lower profit tax revenue. An increase in the profit tax rate triggers a downward adjustment in the commodity tax, but this cannot influence tax revenue. The associated drop also in the large country's tax rate reduces the tax base and profit tax revenue in the small country, and this is sufficiently detrimental to outweigh the direct gain from a higher tax on profits. $^{17}$

In section 2 we considered three different acts of coordination, viz. joint marginal tax increases, harmonization, and a minimum tax rate. Incorporating transportation costs for goods, the Nash reaction curves will be affected, as we saw in Figure 3. However, the new Nash equilibrium still looks qualitatively as before, with the large country choosing the higher commodity tax rate, and with positively-sloped reaction curves. Hence, we may conclude that taking into account costs of transportation of commodities does not

\footnotetext{
${ }^{17}$ For a discussion of such strategic effects and the perverse results they often occasion in an Industrial Organization context see Bulow et al. (1985).
} 
change the qualitative results concerning coordination of commodity taxes in Proposition 2 .

\section{Inspection of illegal cross-border shopping}

Depending on circumstances, cross-border shopping is perceived as illegal or legal. Crossborder trade between, say, the United States and Canada, where Canadians travel to the States to purchase cigarettes etc. is considered illegal by the Canadian authorities. On the contrary, individuals' cross-border trade resulting from the establishment of the Internal Market in the EU is for the major part to be regarded as legal. There are exceptions, though. For instance, Danes shopping in northern Germany may only bring back an amount of certain goods (alcohol, tobacco, etc.) deemed 'for personal consumption'. Otherwise, the undertaking is considered illegal, and the person responsible will be fined. Similar considerations pertain to cross-border trade between the UK and France.

In this section we show how our basic framework can be extended to allow for attempts at containing illegal cross-border shopping. ${ }^{18}$ Let $P$ be the probability that a person who is a resident of the large country is caught when shopping abroad and carrying the good back home. As cross-border shopping immediately yields a tax saving of $T-t$, we assume that the seized person will not only have to pay this differential to the domestic tax authorities, but that he in addition must pay a fine of $(f-1)(T-t) \cdot{ }^{19}$ In total, the extra payment, if caught, amounts to $f(T-t) .{ }^{20}$

Border inspection is not costless for authorities, of course. Indeed, we shall assume that the cost of inspection is a convex function of the number of people caught (and fined) at the border. Denoting the number by $I$, we postulate a cost function $C(I)$, with $C(0)=0, C^{\prime}>0, C^{\prime \prime} \geq 0 .^{21}$

A large country resident living close to the border now faces the following decision. If he purchases the good at home, the price will be $T$. If instead he travels to the border

\footnotetext{
${ }^{18}$ Lovely (1994) also considers enforcement of commodity taxes in a setting with cross-border shopping. However, she only investigates when enforcement is welfare-enhancing, and furthermore there is no tax competition in her model. It should also be mentioned that there is a large related literature on smuggling, perceivedas evasion of trade taxes; see, e.g., Kemp (1976).

${ }^{19}$ The fine parameter $f$ is taken to exceed unity.

${ }^{20} \mathrm{An}$ alternative would be to have the tax and fine paid equal $f T$ rather than $f(T-t)$. However, this alternative formulation complicates the analysis enough to lead us to prefer the present specification.

${ }^{21}$ In general, it can be debated whether the costs of border inspection depend on the number of people caught or the number of people audited. In our setting this makes no difference, since there are no other motives for crossing the border than illegal tax evasion. Also note that we for simplicity ignore any fixed costs involved in setting up border control.
} 
to buy the good, he will in any case have to pay $t$. On top of this, he may be caught at the border; his crime will be detected; and he will have to pay $f(T-t)$ in addition. This occurs with probability $P$; with the residual probability $1-P$, the only cost involved will be $t$.

Assuming risk neutrality on the part of the large country residents, the marginal cross-border shopper, living at a distance $S^{*}$ from the border, is characterized by the equality

$$
T=t+\operatorname{Pf}(T-t)+d S^{*}
$$

The amount of cross-border shopping is therefore

$$
S^{*}=\frac{(1-P f)(T-t)}{d}
$$

Everything else equal, the possibility of detection at the border reduces the amount of cross-border shopping. The same applies for the fining of tax evaders.

The number of cross-border shoppers actually caught is now equal to the product of the probability of detection and the volume of cross-border trade, i.e. $I=P(1-P f)(T-$ $t) / d$. This is the proper argument of the inspection cost function $C()$.

To set up the net revenue function for tax authorities in the large country ${ }^{22}$ we just need to realize that it consists of three terms: (i) the revenue from commodity taxation; (ii) the revenue from fining tax evaders; and (iii) (as a negative term) the inspection costs. We find,

$$
\hat{R}(T, t ; P, f)=T\left[1+b-\frac{(T-t)(1-P f)}{d}\right]+f P(1-P f) \frac{(T-t)^{2}}{d}-C\left(\frac{P(T-t)(1-P f)}{d}\right)
$$

In defining the tax revenue function we allow the tax authorities to set the commodity tax rate $T$, whereas the probability of detection $P$ and the fine $f$ will be treated as exogenous here. ${ }^{23}$

The tax revenue function for the small country is much simpler,

$$
\hat{r}(t, T ; P, f)=t\left[1-b+\frac{(T-t)(1-P f)}{d}\right]
$$

\footnotetext{
${ }^{22}$ In what follows we presuppose that the large country will actually set the higher tax and therefore carry out the border control. The reader may convince herself that adopting the opposite assumption that the small country has the higher tax - will not lead to a feasible tax policy equilibrium.

${ }^{23}$ The size of the fine is taken to be determined by the severity of cross-border shopping as a criminal offense relative to that of other crimes. The probability of detection may in principle be optimized along with the commodity tax. However, pursuing the implications of this is beyond the scope of the present paper (instead, see Hvidt and Nielsen (1998)).
} 
Its tax rate (reaction function) is therefore immediately given by

$$
t=\frac{d(1-b)}{2(1-P f)}+\frac{T}{2}
$$

Compared to the similar expression in section 2, the small country tax authorities take into account not only the commodity tax policy of the large country, but also its inspection policy and the fine assigned to tax evaders.

The first order condition for the large country $\operatorname{tax} T$ is first written in the form

$$
d(1+b)+(1-P f)[t(1-2 P f)-2 T(1-P f)]-C^{\prime} P(1-P f)=0
$$

This equation says that the large country tax will be set so as to trade off the benefits from higher fines and a higher rate in itself against the shrinking of the commodity tax base and higher enforcement costs. Moving terms around, we find

$$
T=\frac{d(1+b)}{2(1-P f)^{2}}+\frac{(1-2 P f) t}{2(1-P f)}-\frac{C^{\prime} P}{2(1-P f)}
$$

With an exogenous and positive detection probability $P,(20)$ can be regarded as the reaction function of the large country. However, it will be superior to take into account that the derivative $C^{\prime}$ of the inspection cost function in principle depends on $T$ (and $t$ ) through its argument $I=P(1-P f)(T-t) / d$. To move ahead, let us with no loss of generality assume that the inspection cost function is quadratic,

$$
C\left(\frac{P(1-P f)(T-t)}{d}\right)=\alpha \frac{P(1-P f)(T-t)}{d}+\beta \frac{P(1-P f)(T-t)^{2}}{d}
$$

Hence, $C^{\prime}=\alpha+2 \beta P(1-P f)(T-t) / d$. Inserting this, we obtain

$$
T=\frac{d(1+b)-\alpha P(1-P f)}{2(1-P f)^{2}\left(1+\beta P^{2} / d\right.}+\frac{\left[(1-2 P f)+2 \beta P^{2}(1-P f) / d\right] t}{2(1-P f)\left(1+\beta P^{2} / d\right.}
$$

as the Nash reaction function, taking the effects of tax rate changes on inspection costs into account.

With this specification we arrive at the following characterization of the non-cooperative commodity tax equilibrium,

PROPOSITION 8. With exogenous enforcement policy, as characterized by a probability of detection $P$, the Nash non-cooperative commodity tax rates are given by

$$
T=\frac{d(3+b-(1-b) 2 P f)+2(1-P f)(1-b) \beta P^{2}-2 \alpha P(1-P f)}{(1-P f)\left[3-2 P f+2(1-P f) \beta P^{2} / d\right]}
$$


and

$$
t=\frac{d(3-b-(1-b) 2 P f)+2(1-P f)(1-b) \beta P^{2}-\alpha P(1-P f)}{(1-P f)\left[3-2 P f+2(1-P f) \beta P^{2} / d\right]}
$$

On the basis of formulas (22a-b) we now wish to investigate how the introduction of border control affects commodity taxes in the two countries. For this purpose, we consider a marginal increase in the probability of detection, $P$, from zero. It is natural to require for the experiment that this increase in $P$ will not in itself lower tax revenue in the large country, ceteris paribus (i.e. when holding constant tax rates $T$ and $t$ ). To find what this requirement entails, we differentiate the tax revenue function wrt. the probability of detection $P$, set $P=0$, and obtain

$$
f T^{N}+\left[f\left(T^{N}-t^{N}\right)-C^{\prime}(0)\right]>0
$$

The first term on the left hand side stands for the effect of a higher $P$ on the tax base; the second term represents the effect on fines; and finally, the third term stands for the effect on the cost of inspection. The sum of these terms should accordingly be positive. Inserting the values for the tax rates from (22a) and (22b), while setting $P$ equal to zero, yields the following inequality from $(23), f>C^{\prime}(0) /[d(1+b)]=\alpha /[d(1+b)]$, where the quadratic cost function has been utilized in the last equality. We now have PROPOSITION 9. If the fine parameter $f$ fulfils (23), then the introduction of inspection at the border leads to an increase in the rate of commodity tax in both countries.

Proof: Total differentiation of first order conditions for the two tax rates yields

$$
\frac{d T}{d P}=\frac{1}{3}\left[f\left(7 T^{N}-4 t^{N}\right)-2 C^{\prime}(0)\right], \quad \frac{d t}{d P}=\frac{1}{3}\left[f\left(2 T^{N}+t^{N}\right)-C^{\prime}(0)\right]
$$

Invoking the formulas for $T^{N}$ and $t^{N}$, plus (23), it is easily seen that both expressions are positive.

Will the extent of cross-border trade increase or decrease as a result of introducing inspection at the border? For medium-sized values of the fine parameter we are able to derive the intuitive result that the amount of cross-border trade goes down, whereas the opposite occurs for larger values of the fine parameter:

PROPOSITION 10. If the fine parameter $f$ belongs to the interval $\left(C^{\prime}(0) /[d(1+b)], 3 C^{\prime}(0) / 4 d b\right)$, then the introduction of border control will lead to a reduction in cross-border shopping. 
If $f$ exceeds $3 C^{\prime}(0) / 4 d b$, then introducing border inspection will increase the volume of cross-border shopping.

Proof: Using the formulas in the previous proof we obtain

$$
\frac{d}{d P}\left(\frac{(T-t)(1-P f)}{d}\right)=\frac{1}{3 d}\left[2 f\left(T^{N}-t^{N}\right)-C^{\prime}(0)\right]
$$

Again, inserting the values of $T^{N}$ and $t^{N}$ delivers the result.

It may be a bit surprising that introducing border control may actually raise crossborder shopping. The reason is that border inspection can induce such a large rise in especially the large country commodity tax, that this may stimulate cross-border shopping more than the emergence of the fine will dampen it.

From expression (18a) for the revenue in the large country we see that everything else equal, an increase in the small country's commodity tax rate will raise net tax revenue in the large country (at least when border control is limited). At the same time, we only consider values of the fine parameter that entail a direct increase in the net tax revenue of the large country of border control, cfr. (23). Given this, it is not surprising that introducing border inspection will indeed raise net revenue in the large country, even when the strategic reaction in the small country's tax is taken into account. It is more surprising that tax revenue in the small country will also increase, even though border control may reduce the extent of cross-border shopping. This is formally stated as

PROPOSITION 11. As long as the fine parameter fulfils (23), the introduction of inspection at the border will benefit net tax revenue in both countries.

Proof: Direct differentiation of net revenue expressions, applying $P=0$, yields

$$
\frac{d \hat{R}}{d P}=\frac{T^{N}-t^{N}}{d}\left[f T^{N}+f\left(T^{N}-t^{N}\right)-C^{\prime}(0)\right]+\frac{T^{N}}{d} \frac{d t}{d P}
$$

and

$$
\frac{d \hat{r}}{d P}=\frac{t}{3 d}\left[f\left(4 T^{N}-t^{N}\right)-C^{\prime}(0)\right]
$$

Again, applying the requirement (23) produces the result.

Figure 4 illustrates how the introduction of border control affects reaction curves and the Nash commodity tax equilibrium. In the figure we have once again inserted the reaction curves associated with the simple model in section 2 . These curves are again 
denoted by $L_{o}$ and $l_{o}$, and they produce the Nash equilibrium $N_{o}$. An examination of the two reaction curves will reveal that the introduction of inspection at the border will move the small country reaction curve upwards, while that part of the large country reaction curve which lies below the $45^{\circ}$ line will move out (when (23) is fulfilled). Hence, the new Nash equilibrium with border inspection will be point $N_{P}$ in the figure. Per construction, the new equilibrium indeed features a higher tax rate for both countries.

Concerning coordination of commodity taxes it is clear from Figure 4 and our computations above (in particular Proposition 8) that it is still the large country which chooses the higher commodity tax rate. Further, the sign of the slopes of the reaction curves is positive as before. Hence, we conclude that the qualitative effects of, respectively, small forced increases in the two commodity tax rates, tax harmonization, and a minimum tax rate on tax revenues in the two countries will be as in the benchmark model.

Above, we have treated enforcement policy, i.e. the probability of detection, as exogenous. It would be interesting to look at the choice of the level of enforcement. Pursuing an investigation of optimal enforcement and the interesting strategic interaction between enforcement and commodity tax rates in either country will, though, lead us too far astray. Instead, see Hvidt and Nielsen (1998).

\section{Conclusion}

This paper has set up a simple model of commodity tax competition in the face of possibilities for cross-border shopping. The model has two countries, one larger than the other in geographical extent. This asymmetry produces a wedge between the commodity tax rates in the two countries and therefore some cross-border shopping. We analyzed the effects on tax revenues in the two countries of several acts of tax coordination, including marginal increases in the two tax rates, rate harmonization, and a minimum tax rate requirement. Even though our benchmark model is considerably simpler than the already simple framework of Kanbur and Keen (1993), our conclusions as to the effects of tax coordination correspond well to their results.

An important objective of the paper was, however, to move beyond the simple benchmark model in order to incorporate costs of transportation for goods (and not only persons) as well as inspection at the border to contain (illegal) cross-border shopping. We accomplished this, reaching the general insights that both transportation costs of goods and border inspection will tend to increase commodity tax rates (and therefore 
tax revenues). Our conclusions as to the qualitative consequences of coordination of tax policies were not affected by these extensions of the benchmark model.

Technological development and continuing economic integration seem to be lowering the relative cost of transporting goods from one country to (the border of) another. Our analysis in section 3 shows that this should intensify commodity tax competition and enhance the pressure to reduce commodity taxes where cross-border shopping poses a threat. As is well-known, the member countries of the EU abolished border control by January 1, 1993. Our results in section 4 point in the direction that this step has also led to increased commodity tax competition between member countries and a downward pressure on their tax rates. It is worth noting that several EU countries have since the mid-1980's lowered excise taxes on a range of goods which may be particularly sensitive to cross-border shopping (alcohol, tobacco, etc.). However, VAT rates have rather increased in line with an increased need to finance public sector outlays.

What will happen to commodity taxation in the EU in the future is uncertain. The current 'transitional system' in which trade between registered firms is taxed according to the destination principle, whereas this principle is not enforced for individuals, may continue for still some time. Or commodity taxation may at some point switch from the destination principle to an origin principle. It is well-known that whereas the destination principle is sensitive to cross-border shopping, this is not the case with the origin principle. The latter principle is sensitive to transfer pricing problems, though (see Genser and Schulze (1997) and Gordon and Nielsen (1997)).

\section{References}

Bulow, J., J. D. Geanakoplos and P. D. Klemperer, 1985, Multimarket oligopoly: Strategic substitutes and complements, Journal of Political Economy 93, 488-511,

Christiansen, V., 1994, Cross-border shopping and the optimum commodity tax in a competitive and a monopoly market, Scandinavian Journal of Economics 96, $329-341$

deCrombrugghe, A. and H. Tulkens, 1986, On Pareto-improving tax changes under fiscal competition, Journal of Public Economics 41, 335-350

European Communities-Commission, 1985, Completing the internal market, COM(85) 310 
Fehr, H., C. Rosenberg and W. Wiegard, 1995, Welfare effects of value-added tax harmonization in Europe, Berlin, Sprenger

Genser, B. and G. Schulze, 1995, Transfer pricing under an origin-based VAT system, Diskussionsbeitrag, Serie II, Nr. 271, Universität Konstanz, May 1995

Gordon, R. H. and S. B. Nielsen, 1997, Tax evasion in an open economy: Valueadded vs. income taxation, Journal of Public Economics 66, 173-197

Haufler, A., 1996, Tax coordination with different preferences for public goods: Conflict or harmony of interest? International Tax and Public Finance 3, 5-28

Hvidt, M. and S. B. Nielsen, 1998, Border inspection and commodity tax competition, mimeo, EPRU, Copenhagen Business School

Kanbur, R. and M. Keen, 1993, Jeux sans frontières: Tax competition and tax coordination when countries differ in size, American Economic Review 83, 877-892

Keen, M., 1993, The welfare economics of tax coordination in the European Community, Fiscal Studies 14/2, 15-36

Keen, M. and S. Smith, 1996, The future of the value-added tax in the European Union, Economic Policy 23, 373-420

Kemp, M., 1976, Smuggling and optimal commercial policy, Journal of Public Economics 5, 381-384 15-36

Lockwood, B., 1993, Tax competition in a customs union under destination and origin principles, Journal of Public Economics 53, 141-162

Lovely, M.E., 1994, Crossing the border: does commodity tax evasion reduce welfare and can enforcement improve it? Canadian Journal of Economics 27, 157-174

Mintz, J. and H. Tulkens, 1986, Commodity tax competition between member states of a federation, Journal of Public Economics 29, 133-172

Trandel, G.A., 1994, Interstate commodity tax differentials and the distribution of residents, Journal of Public Economics 53, 435-457 


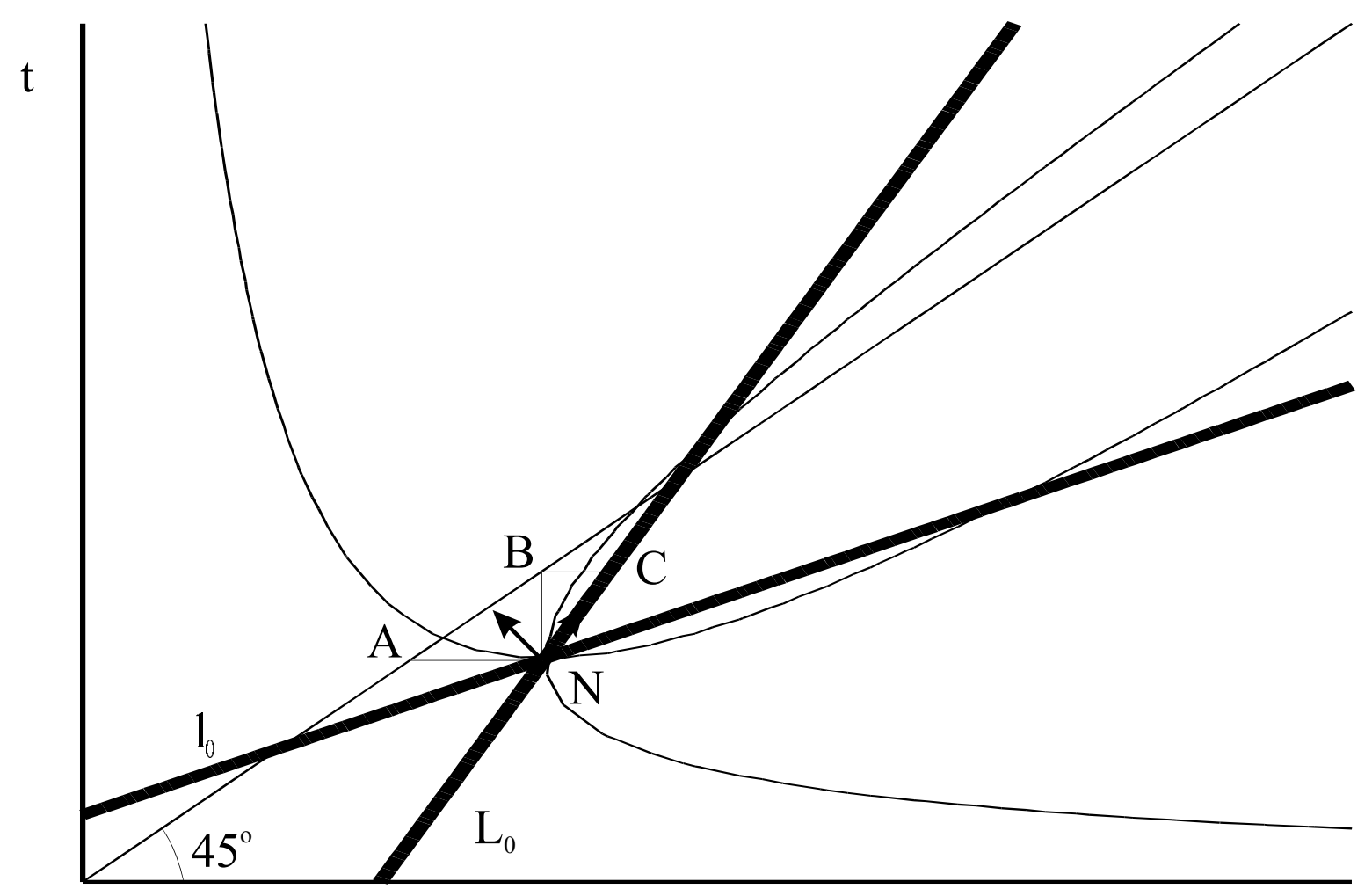

Figure 1: Nash equilibrium and coordination in the benchmark model.

$\mathrm{T}$

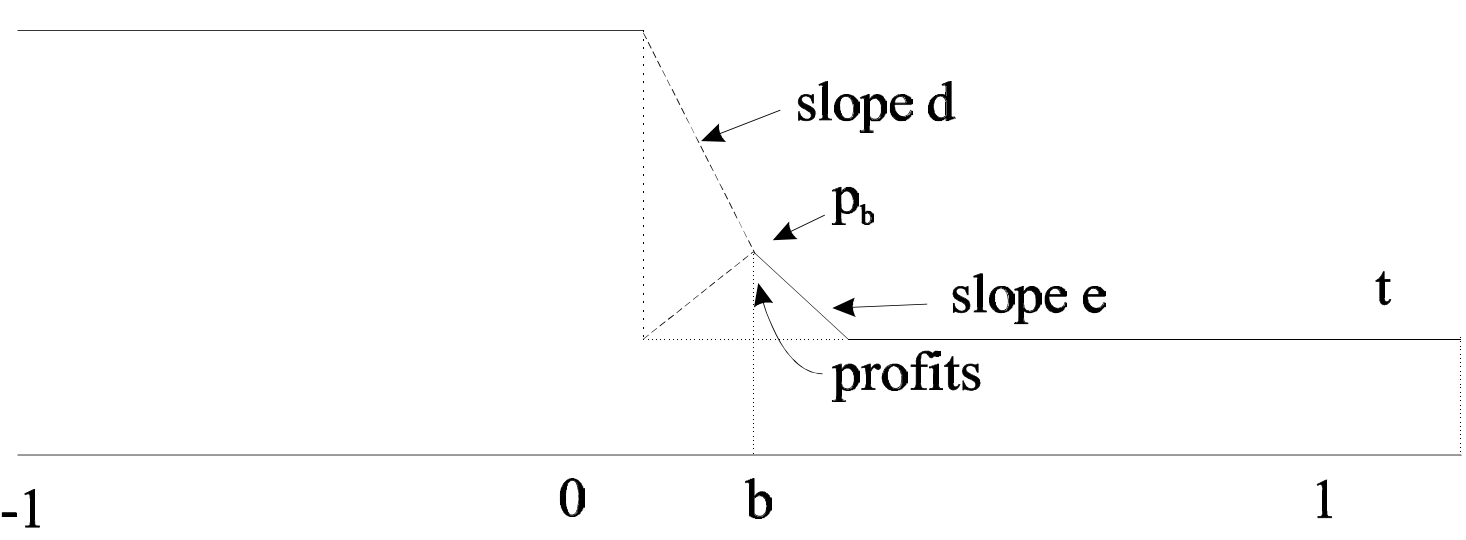

Figure 2: Pricing with cross-border shopping and transportation costs for goods. 


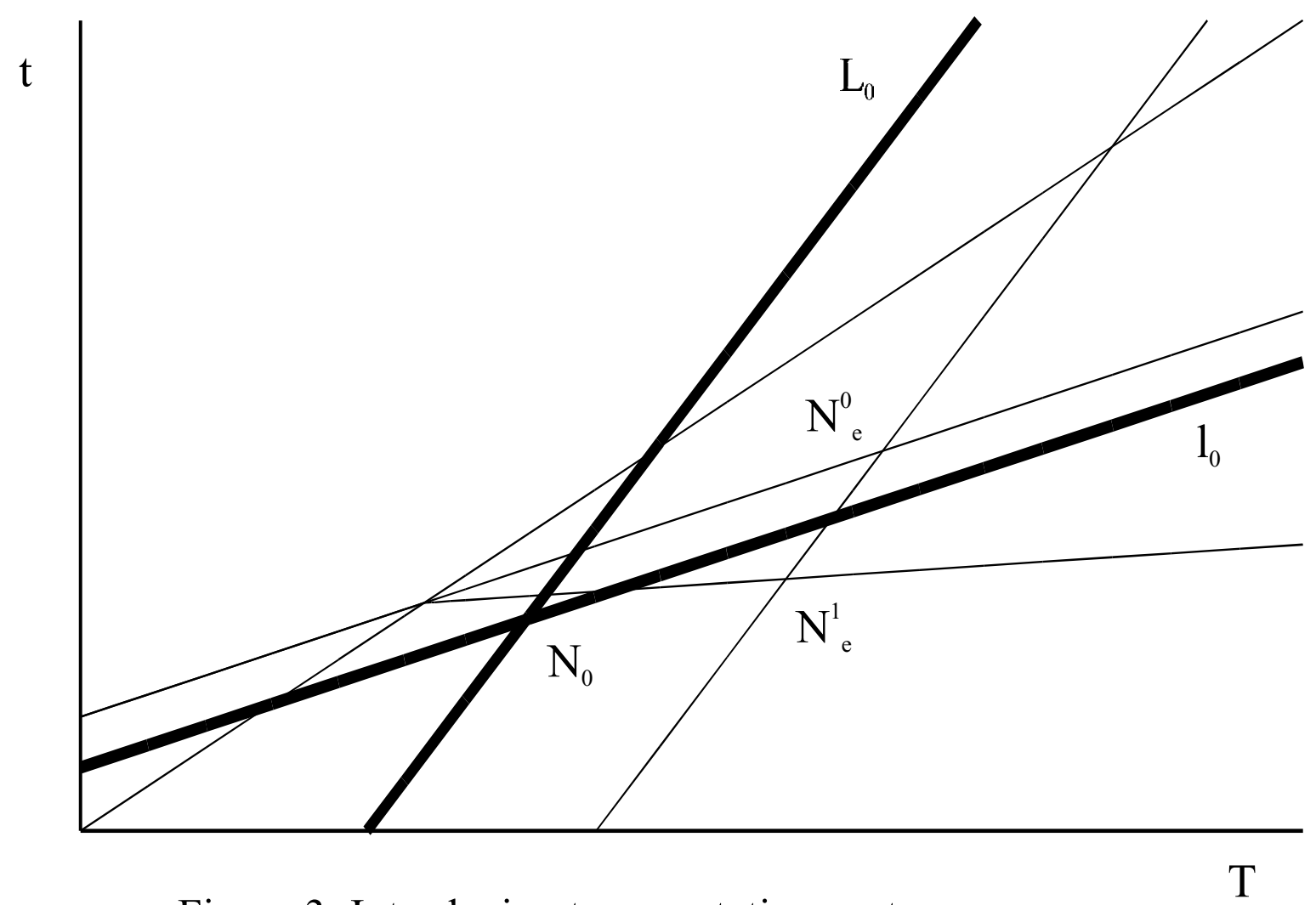

Figure 3: Introducing transportation costs.

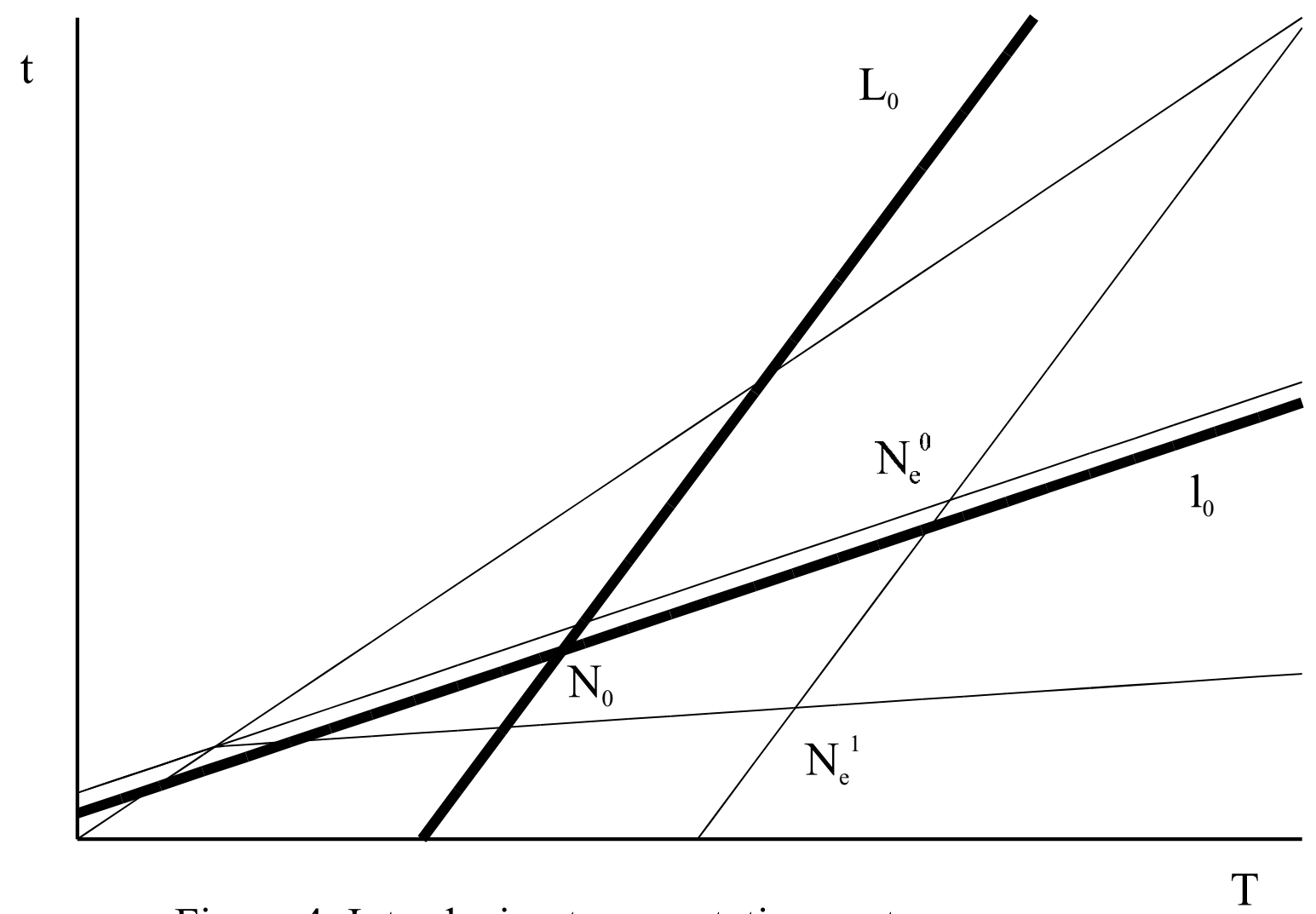

Figure 4: Introducing transportation costs; $b$ large and $\pi=1$. 